\title{
Acidosis láctica por metformina desencadenada por una insuficiencia renal aguda
}

\section{Metformin-induced lactic acidosis due to acute renal failure}

\author{
M.D. Macías-Robles ${ }^{1}$, C. Maciá-Bobes ${ }^{2}$, R. Yano-Escudero ${ }^{3}$, \\ O. Fernández-Diéguez ${ }^{1}$, O. Álvarez-Lecue ${ }^{4}$
}

\section{RESUMEN}

La acidosis láctica es una complicación grave pero infrecuente asociada al empleo de metformina. Se discuten los mecanismos fisiopatológicos implicados en la acidosis láctica, con especial atención al papel potencial del fármaco.

Presentamos un caso severo de este efecto secundario de la metformina en una paciente con diabetes tipo 2 que ingresó en el Servicio de Urgencias Hospitalario por un cuadro de insuficiencia renal aguda. El diagnóstico quedó apoyado por unos niveles séricos elevados de la biguanida, procedimiento escasamente utilizado en la práctica clínica.

El tratamiento consiste en suspender la administración del fármaco e iniciar de forma inmediata la hemodiálisis con bicarbonato, lo cual proporciona un tratamiento sintomático y etiológico al eliminar del suero tanto el lactato como el antidiabético oral.

Los síntomas de la acidosis láctica por metformina son inespecíficos y el comienzo es sutil, lo que hace necesario un alto nivel de sospecha para establecer un diagnostico precoz.

Palabras clave. Metformina. Acidosis láctica. Insuficiencia renal aguda.

\begin{abstract}
Lactic acidosis is a serious but uncommon side effect of metformin use. We discuss the pathophysiological mechanisms of lactic acidosis with particular regard to the role played by the drug as a potential cause of the entity.
\end{abstract}

We report on a severe case of this kind of drug toxicity in a patient with type 2 diabetes mellitus, admitted to the emergency department with acute renal failure symptoms. The diagnosis was supported by elevated serum levels of the biguanide, a procedure scarcely used in clinical practice.

The management of this complication consists in drug discontinuation and hemodialysis with bicarbonate that provides symptomatic and ethiological treatment by removing both the lactate and the hypoglycemic agent from the serum.

Since the symptoms of metformin-associated lactic acidosis are unspecific and its onset is subtle, a high level of suspicion is needed to establish an early diagnosis.

Key words. Metformin. Lactic acidosis. Acute renal failure.
1. Servicio de Urgencias

2. Sección de Endocrinología

3. Unidad de Cuidados Intensivos

4. Servicio de Bioquímica

Hospital San Agustín. Avilés. Asturias

\section{Correspondencia:}

Carmen Maciá-Bobes

C/ Pablo Laloux, 13, esc. sur, $6^{\circ} \mathrm{A}$

33405 Salinas (Asturias)

E-mail: cmacb@arrakis.es

Recepción: 4 de enero de 2011

Aceptación provisional: 31 de enero de 2011

Aceptación definitiva: 17 de febrero de 2011 


\section{INTRODUCCIÓN}

La metformina es una biguanida utilizada como fármaco de primera línea en el tratamiento de la diabetes mellitus tipo 2 (DM-2). La acidosis láctica (AL) asociada a su empleo se caracteriza por una baja frecuencia de presentación (8 casos/100.000 pacientes tratados/año), pero una alta mortalidad (20-50\%) $)^{1,2}$. La AL se produce generalmente por la acumulación de metformina en aquellos pacientes que desarrollan insuficiencia renal aguda (IRA), mientras que la intoxicación voluntaria es menos frecuente ${ }^{1}$. Se presenta el caso de una paciente tratada con metformina que desarrolló una IRA de causa multifactorial, $\mathrm{y}$, como consecuencia, una AL; y se revisan los mecanismos fisiopatológicos probablemente implicados.

\section{CASO CLÍNICO}

Mujer de 72 años, con DM-2, hipertensión arterial y cardiopatía isquémica, en tratamiento con metformina ( $850 \mathrm{mg} / 12$ horas), enalapril (5 $\mathrm{mg} /$ día), furosemida ( $20 \mathrm{mg} /$ día), ácido acetilsalicílico (100 mg/día) y omeprazol $(20 \mathrm{mg} /$ día). Acudió al Servicio de Urgencias Hospitalario (SUH) por vómitos de una semana de evolución, sin fiebre, asociados en los últimos cuatro días a dolor en las extremidades inferiores, debilidad y malestar abdominal difuso. Ambulatoriamente fue tratada con diclofenaco y metoclopramida, y este tratamiento se siguió de deposiciones líquidas y oliguria. En la exploración física la paciente estaba consciente, afebril, su tensión arterial era de $80 / 50 \mathrm{mmHg}$ y la saturación de oxígeno por pulsioximetría de $97 \%$. Presentaba taquipnea (25 respiraciones/minuto), y tanto la auscultación cardiopulmonar como la palpación abdominal eran normales. En los análisis de sangre se objetivó una glucosa no basal de $347 \mathrm{mg} / \mathrm{dL}$ (70-110), urea: $160 \mathrm{mg} / \mathrm{dL}$ (13-71), creatinina: $4,38 \mathrm{mg} / \mathrm{dL}$ $(0,50-0,90)$, sodio: $126 \mathrm{mmol} / \mathrm{L}$ (133-145), potasio: $8,79 \mathrm{mmol} / \mathrm{L}(3,7-5,40)$, cloro: $83 \mathrm{mmol} / \mathrm{L}$ (94110), lactato: $176 \mathrm{mg} / \mathrm{dL}(5,7-22)$, anión GAP: 33,3 $\mathrm{mmol} / \mathrm{L}(8-16)$, pH: $7,14(7,35-7,45)$ y bicarbonato: $9,7 \mathrm{mmol} / \mathrm{L}(20-26)$. La lactatodeshidrogenasa, creatinquinasa, amilasa, calcio, magnesio, hemograma y coagulación eran normales. Dos hemocultivos y un coprocultivo fueron negativos. El nivel de metformina por cromatografía líquida de alta resolución fue de $43 \mathrm{mg} / \mathrm{L}$ (valores terapéuticos: 0,1-1,3 mg/L y tóxicos: 5-10 mg/L). En el electrocardiograma se objetivó un ensan- chamiento del complejo QRS y un aplanamiento de la onda $P$. La radiografía de tórax y la ecografía abdominal no mostraron alteraciones. Se instauró tratamiento con reposición intravenosa de volumen, bicarbonato, salbutamol nebulizado y glucosa con insulina para corregir la hiperpotasemia. Puesto que la paciente seguía hipotensa y en anuria se inició una perfusión de noradrenalina $(0,5 \mu \mathrm{g} / \mathrm{kg} / \mathrm{min})$, y se la trasladó a la Unidad de Cuidados Intensivos. Allí se le realizó hemodiálisis y su situación clínica mejoró rápidamente, se normalizaron progresivamente la función renal y las alteraciones hidroelectrolíticas, y la AL revirtió.

\section{DISCUSIÓN}

La AL se caracteriza por una elevada concentración de lactato sanguíneo asociada a una acidosis metabólica con hiato aniónico aumentado. La etiología se debe a un aumento de la producción (tipo A) o a una disminución de la utilización (tipo B) del ácido láctico. La AL tipo A se produce cuando existe un déficit de oxígeno, usualmente debido a una alteración en la oxigenación/ perfusión, mientras que la $\mathrm{AL}$ tipo B se observa cuando se compromete el metabolismo del lactato en ausencia de hipoxia, y está causada habitualmente por una acumulación de ciertos fármacos, entre ellos la metformina ${ }^{2}$.

La AL por metformina es una condición metabólica poco frecuente pero de alta mortalidad ${ }^{1,2}$. Los mecanismos fisiopatológicos continúan aún hoy siendo controvertidos. La unión de metformina a las proteínas plasmáticas es escasa, y el $90 \%$ se elimina mediante secreción tubular, de modo que los medicamentos que disminuyen su aclaramiento renal (digoxina, ranitidina, amiloride o contrastes yodados), o, más frecuentemente, una IRA pueden aumentar los niveles plasmáticos de metformina $^{3,4}$. Por otra parte, la biguanida disminuye la gluconeogénesis y la actividad de la piruvato-deshidrogenasa, y altera el metabolismo oxidativo y el transporte a través de las membranas mitocondriales de los agentes óxido-reductores, con lo que se inhibe el metabolismo aerobio. Al mismo tiempo incrementa la producción intestinal de lactato sin alterar la liberación del mis- 
mo desde el músculo. Todo ello contribuye a un aumento del ácido láctico ${ }^{5-7}$.

En la práctica, se pueden distinguir tres situaciones con un pronóstico diferente. En la primera, la metformina es responsable de la AL debido a una sobredosis voluntaria o accidental, y el pronóstico es bueno; en la segunda, la asociación entre el fármaco y la AL es casual en su origen, y esta última está condicionada por un fallo orgánico subyacente (cardiopatía isquémica, shock de cualquier etiología, insuficiencia respiratoria, cardiaca o hepática); en la tercera situación existe una causa de AL, agravada por una IRA que conduce a la acumulación de metformina ${ }^{5,7}$. Para que se produzca la $\mathrm{AL}$ no son estrictamente necesarios otros factores condicionantes además de la metformina ${ }^{8}$. Sin embargo, de existir, son éstos los que más influyen en el pronóstico; de ahí que las dos últimas situaciones sean las que presentan una mortalidad más elevada $(40-50 \%)^{1,7}$.

Los síntomas de la AL son inespecíficos (náuseas, vómitos, diarrea, molestias abdominales y mialgias) y el comienzo es sutil, lo que hace necesario un alto nivel de sospecha para poder establecer un diagnóstico precoz. El cuadro clínico de la paciente descrita se caracterizó por una IRA con hiperpotasemia grave asociada a una AL con hiato aniónico elevado. El factor desencadenante más probable fue el doble tratamiento con el inhibidor de la enzima convertidora de la angiotensina (IECA) y el antiinflamatorio no esteroideo, lo cual, asociado a la hipovolemia, precipitó el fracaso renal. La existencia de hiperpotasemia severa, una ingesta hídrica escasa asociada a pérdidas gastrointestinales y la toma de un diurético, avalan este mecanismo. De hecho, se ha descrito la toma concomitante de diurético hasta en el $70 \%$ de los casos de IRA secundaria a IECA ${ }^{9}$. Como consecuencia de la IRA se produjo el acúmulo de la metformina y la AL. El diagnóstico quedó apoyado por unos niveles séricos elevados de metformina, procedimiento escasamente realizado en la práctica clínica ${ }^{3,10}$.

La administración intravenosa de bicarbonato como método para corregir la
AL es habitual, pero discutida porque generalmente son necesarias altas dosis que pueden producir hipernatremia, hiperosmolaridad y sobrecarga de volumen, especialmente si la perfusión renal es deficiente; además aumenta la producción de $\mathrm{CO}_{2}$, disminuye el $\mathrm{pH}$ intracelular, y también la contractilidad miocárdica y el gasto cardíaco. El tratamiento de la AL por metformina consiste en suspender la administración del fármaco e iniciar de forma inmediata la hemodiálisis con bicarbonato ya que proporciona un tratamiento sintomático y etiológico, al eliminar tanto el lactato como la metformina, y corregir las alteraciones hidroelectrolíticas ${ }^{1,5}$. La escasa unión de la biguanida a las proteínas plasmáticas la hace fácilmente dializable, por lo que una instauración precoz de este tratamiento contribuye a mejorar el pronóstico del paciente.

Por último, queremos subrayar que es esencial para un uso seguro de la metformina mejorar la educación tanto de los pacientes que reciben tratamiento como de los médicos que los tratan. Destacamos que es necesario suspender el uso de este antidiabético oral cuando se prevea una situación de disfunción renal. Y también la necesidad de que en los SUH se conozcan tanto los factores de riesgo de la sobredosis accidental de metformina como la posibilidad de que ésta precipite una AL, ya que un diagnostico precoz contribuirá a aplicar un tratamiento agresivo eficaz en esta urgencia vital.

\section{BIBLIOGRAFÍA}

1. Seidowsky A, Nseir S, Houdret N, Fourrier F. Metformin-associated lactic acidosis: a prognostic and therapeutic study. Crit Care Med 2009; 37: 2191-2196.

2. Ortega J, Ambrós A, Martín C, Ruiz F, Portilla M, GómEz L. Sobredosis de metformina secundaria a insuficiencia renal aguda. Med Intensiva 2007; 31: 521-525.

3. Runge S, Mayerle J, Warnke C, Robinson D, Roser M, FELIX SB et al. Metformin-associated lactic acidosis in patients with renal impairment solely due to drug accumulation? Diabetes Obes Metab 2008; 10: 91-93. 
4. De la Maza L, García VM, Álvarez P, Pi J, CastiLLO L, RuIz E. Acidosis láctica por metformina. Endocrinol Nutr 2007; 54: 325-327.

5. LALAU JD. Lactic acidosis induced by metformin: incidence, management and prevention. Drug Saf 2010; 33: 727-740.

6. Sánchez-Rubio J, Manteiga E, Martínez O. Metformin-induced acute lactic acidosis. Farm Hosp 2007; 31: 71-72.

7. Orban JC, Ghaddab A, Chatti O, Ichai C. Metformin-associated lactic acidosis. Ann $\mathrm{Fr}$ Anesth Reanim 2006; 25: 1046-1052.
8. Wills BK, Bryant SM, Buckley P, Seo B. Can acute overdose of metformin lead to lactic acidosis? Am J Emerg Med 2010; 28: 857-861.

9. Calviño JA, Romero R, Novoa D, Güimil D, CorDAL T, SÁnchez-Guisande D. Fracaso renal agudo asociado a antiinflamatorios no esteroideos e inhibidores del enzima conversor de la angiotensina. Nefrología 1997; 17: 405-410.

10. Holanda MS, Superviola B, González A, Marco JM, UGARTE P. Acidosis láctica grave asociada a intoxicación por metformina. Nutr Hosp 2007; 22: 124-125. 